\title{
PARÂMETROS SENSORIAIS DE CONSERVA DE PALMITOS BASAL E FOLIAR DE PUPUNHA ACIDIFICADA COM ÁCIDO ACÉTICO
}

\section{SENSORY PARAMETERS OF CONSERVE OF BASAL AND FOLIACEUS PALM OF PUPUNHA ACIDIFIED WITH ACETIC ACID}

\author{
Paula Porrelli Moreira da Silva ${ }^{1}$; Marta Helena Fillet Spoto ${ }^{2}$; Edinéia Gomes da SILVA ${ }^{3}$, Thássia Larissa \\ Cardoso ${ }^{4}$ \\ ${ }^{1}$ Universidade de São Paulo, Centro de Energia Nuclear na Agricultura - USP/CENA - Piracicaba/SP - \\ Brasil pporrelli@uol.com.br \\ ${ }^{2,3,4}$ Universidade de São Paulo, Escola Superior de Agricultura Luiz de Queiroz - USP/ESALQ - \\ Piracicaba/SP - Brasil mhfspoto@ usp.br
}

\begin{abstract}
Resumo
A pupunha, nativa da Amazônia, apresenta características de precocidade, rusticidade $e$ perfilhamento, fornece palmito de ótima qualidade, diferindo dos demais pelo sabor adocicado e cor amarelada. Devido a este fato, tal produto não é bem aceito sensorialmente pois o paladar dos consumidores está acostumado a conservas de palmito mais salgadas. A indústria utiliza tradicionalmente o ácido cítrico no processamento de palmitos em conserva, porém, o ácido acético tem a capacidade de mascarar o sabor adocicado do palmito de pupunha. O objetivo deste estudo foi avaliar sensorialmente conservas de palmito basal e foliar acidificadas com ácido acético, comparadas às processadas com o ácido cítrico. As palmeiras foram cultivadas em área experimental da ESALQ/USP e teve as características sensoriais do palmito basal e foliar de pupunha analisadas em cinco períodos de armazenamento (1, 15, 30, 60, 90 dias). Os valores médios para o atributo impressão global das amostras evidenciaram menor aceitação das conservas de palmito basal acidificada com ácido acético, classificadas como "desgostei ligeiramente", porém não diferiram estatísticamente dos demais produtos, que foram bem aceitos em todos os períodos avaliados, destacando-se as amostras de palmito foliar. $O$ ácido acético conferiu às amostras gosto ligeiramente amargo, porém não interferiu negativamente em suas avaliações, mostrando que pode ser utilizado em substituição ao ácido cítrico. Ainda, foi constatado que o palmito basal pode ser comercializado em igual patamar ao foliar, por não haver diferença estatística entre eles.
\end{abstract}

Palavras-chave: Bactris gasipaes, teste de aceitação, processamento térmico, ácido cítrico.

\section{Introdução}

O palmito vem sendo utilizado na alimentação dos brasileiros desde tempos remotos, no início pelos indígenas e posteriormente pelos colonizadores portugueses e escravos. O seu consumo se acentuou durante a expansão do cultivo de café, ocorrida no Sul e Sudeste do país, onde a 
palmeira juçara (Euterpe edulis) foi utilizada para construção de moradias de colonos utilizando o caule para parede e assoalho, a palha (folha) para cobertura das casas e o palmito como alimento (YUYAMA, 2005). Suas características sensoriais peculiares fizeram com que o consumo fosse sempre crescente até atingir uma grande demanda.

No Brasil, as palmeiras mais exploradas são as do gênero Euterpe, onde estão inseridas as palmeiras juçara (Euterpe edulis), nativa da Mata Atlântica e a açaí (Euterpe oleracea), nativa da Amazônia. Estas espécies vêm sendo preferidas para consumo devido ao fato de que estão no mercado há muitos anos, o que condicionou o gosto do consumidor. No entanto, devido à alta taxa de exploração e ao baixo poder de regeneração destas palmeiras, espécies mais precoces e que produzam bom palmito têm sido buscadas (BOVI, 1997). Dentre elas a pupunha (Bactris gasipaes), nativa da Amazônia, tem merecido destaque.

A palmeira B. gasipaes adapta-se a diferentes condições ecológicas. Ocorre próximo ao nível do mar até cerca de 2000 m de altitude (ALMEYDA e MARTIN, 1980). Desenvolve-se bem em temperaturas tropicais entre $24{ }^{\circ} \mathrm{C}$ e $28{ }^{\circ} \mathrm{C}$ e é encontrada em áreas que se diferenciam consideravelmente quanto ao regime anual de chuvas, desde 1500 até $6000 \mathrm{~mm}$, embora cresça melhor em áreas com chuvas abundantes e bem distribuídas (MORA URPÍ, 1982).

A pupunha foi domesticada pelos índios da Amazônia, tendo seus frutos utilizados principalmente na alimentação como fonte de nutrientes e de energia (amido e lipídios), bem como de matéria-prima para a agroindústria. Em alguns lugares da Amazônia e do noroeste da América do Sul a pupunheira já foi o cultivo principal, dada a sua produtividade e a preferência pelos povos nativos (YUYAMA, 1997). Tratando-se de uma espécie domesticada e adaptada à condição amazônica, mostrou uma grande plasticidade e adaptou-se muito bem nas outras regiões brasileiras, com exceção do Rio Grande do Sul, onde o seu crescimento é mais lento devido ao clima frio ou devido ao período prolongado de estiagem.

O palmito é constituído por três partes: a) caulinar (basal), de maior diâmetro, situada na região mais baixa do talo do palmito; b) apical, situada no ápice do talo, apresenta aspecto foliar e diâmetro reduzido; c) creme de palmito, coração ou tolete, localizada na região intermediária do talo entre as partes caulinar e apical, é a porção mais nobre do palmito, possuindo maior valor comercial (CHAIMSOHN, 2001; RAUPP, 2001).

A utilização industrial das palmeiras pupunha em substituição à juçara e açaí considera apenas o palmito foliar da planta, reservando à parte basal uma destinação como subproduto. A pupunha, por apresentar sabor mais adocicado, não conta com boa aceitação do mercado consumidor já acostumado com o sabor das outras palmeiras, necessitando-se de uma tecnologia de processamento que mascare tal sabor, como a utilização do ácido orgânico acético como agente acidificante. 
O ácido acético, devido à sua baixa solubilidade, ao seu sabor e à sua baixa toxicidade ao organismo humano, é bastante eficiente e largamente utilizado como acidulante e conservador de alimentos. Sua ação conservadora é atribuída à queda de $\mathrm{pH}$ do meio, e sua atividade antimicrobiana inicia-se em concentrações superiores a $5 \mathrm{~g} \mathrm{~kg}^{-1}$ (SOCCOL, 2002).

Os testes sensoriais são de extrema importância, pois podem ser incluídos entre os de garantia de qualidade do produto, por ser uma medida multidimensional integrada capaz de detectar, de forma rápida, particularidades sensoriais que não podem ser detectadas por outros procedimentos analíticos e ainda serem capazes de avaliar se um produto é bem aceito ou não (MUÑOZ et al., 1992).

O presente estudo teve como objetivo avaliar sensorialmente a qualidade do palmito basal e foliar de pupunha, acidificado com ácido acético e comparado com o ácido cítrico, largamente utilizado nas indústrias do palmito.

\section{Material e Métodos}

\section{Processamento}

Os palmitos de pupunha foram obtidos em estação experimental da ESALQ/USP e processados no Departamento Agroindústria Alimentos e Nutrição da instituição. O processamento foi constituído pelas seguintes etapas: a) remoção das capas da pupunha com ajuda de facões de aço inoxidável; b) divisão das toras em duas porções comestíveis: intermediária (tolete) e basal (coração). Os toletes foram cortados em unidades de $9 \mathrm{~cm}$ de comprimento, e a porção basal foi fatiada em rodelas de $2 \mathrm{~cm}$ de espessura; tomou-se o cuidado de não incorporar as partes endurecidas. Os cortes foram feitos com facões de aço inoxidável, contando com o auxílio de um gabarito de plástico para a padronização do comprimento dos toletes em $9 \mathrm{~cm}$.

Imediatamente após o corte, os toletes e a parte basal foram limpos, divididos pela metade e imersos em soluções de espera com $5 \%$ de cloreto de sódio $(\mathrm{NaCl})$ e $1 \%$ de ácido cítrico ou acético até a próxima etapa do processamento. Realizou-se em seguida o branqueamento, em que os produtos foram imersos durante 20 minutos em salmouras acidificadas (3\% de $\mathrm{NaCl}$ e $0,2 \%$ de ácido cítrico/acético) a $100^{\circ} \mathrm{C}$, contidas em panelas de aço inoxidável. Os produtos foram, então, resfriados em peneiras em temperatura ambiente, a fim de escoar o excesso de salmoura e evitar o sobreaquecimento do produto.

Os toletes e palmitos basal de pupunha foram envasados em recipientes de vidro $(13,5 \mathrm{~cm}$ de altura por $8 \mathrm{~cm}$ de diâmetro) fazendo uso da proporção $350 \mathrm{~g}$ de palmito para $230 \mathrm{~g}$ de salmoura quente $\left(100^{\circ} \mathrm{C}\right)$ e acidificada com $2,5 \%$ de cloreto de sódio $(\mathrm{NaCl})$. Realizou-se curva de titulação 
de acordo com Zapata e Quast (1975) para a obtenção da concentração de ácido (cítrico e acético) a ser acrescentada na salmoura.

A etapa de exaustão foi feita em panelas de aço inoxidável com água em ebulição, até que o centro geométrico do recipiente que continha o palmito atingisse entre 85 e $87^{\circ} \mathrm{C}$. Imediatamente após a exaustão, os vidros foram recravados a fim de evitar a queda da temperatura e a diminuição do vácuo no produto final. Em seguida, foi feito o tratamento térmico através de imersão em água em ebulição, contida em recipientes de aço inoxidável, durante 30 minutos.

Após este período, os vidros foram colocados em tanques com água fria clorada com o objetivo de resfriá-los. O armazenamento foi realizado em local seco e à temperatura ambiente, até os períodos de análises.

Portanto, este experimento foi efetivado com quatro tratamentos, a saber:

1. Conserva de palmito basal (coração) de pupunha em ácido cítrico

2. Conserva de palmito basal (coração) de pupunha em ácido acético

3. Conserva de palmito foliar (tolete) de pupunha em ácido cítrico

4. Conserva de palmito foliar (tolete) de pupunha em ácido acético

\section{Análise sensorial - Teste de aceitação com escala hedônica}

Cinquenta provadores, entre estudantes e funcionários do Departamento de Agroindústria, Alimentos e Nutrição da Escola Superior de Agricultura “Luiz de Queiroz” ESALQ/USP, foram voluntários para a análise sensorial, em cada sessão, considerando-se a sua disponibilidade e o seu interesse para avaliar a diferença sensorial entre as conservas de pupunha.

As avaliações foram feitas nos períodos 1, 15, 30, 60 e 90 dias de armazenamento. Em cada sessão de avaliação, para cada provador, foram servidas quatro amostras que representaram os tratamentos de cada tipo de corte (coração e tolete) e de acidificação (ácido cítrico e ácido acético).

Para a realização dos testes sensoriais, pedaços de palmito de pupunha de $3 \mathrm{~cm}$ de comprimento de cada tratamento foram servidos à temperatura ambiente, em copos plásticos brancos de $50 \mathrm{~mL}$ de capacidade, e com palitos de madeira para auxiliar na degustação. Os recipientes foram codificados com números de três dígitos, tendo-se o cuidado de realizar um delineamento experimental em Quadrados Latinos $(4 \mathrm{x} 4)$ com o objetivo de se eliminar eventual erro de provador não treinado, segundo Cochran e Cox (1957).

Cada provador foi orientado a provar as amostras da esquerda para a direita, tomar água entre as amostras e apresentar na escala hedônica estruturada mista de nove pontos o quanto gostou ou desgostou de cada amostra para a impressão global (aparência, sabor, textura e odor) dos produtos ( 9 = gostei muitíssimo; 1 = desgostei muitíssimo), de acordo com Meilgaard (1991). 
Todos os indivíduos provaram as amostras em cabines individuais equipadas com lâmpadas coloridas para a sua avaliação global (Figura 1).

Figura 1 - Modelo da ficha de análise sensorial utilizando a escala hedônica de nove pontos

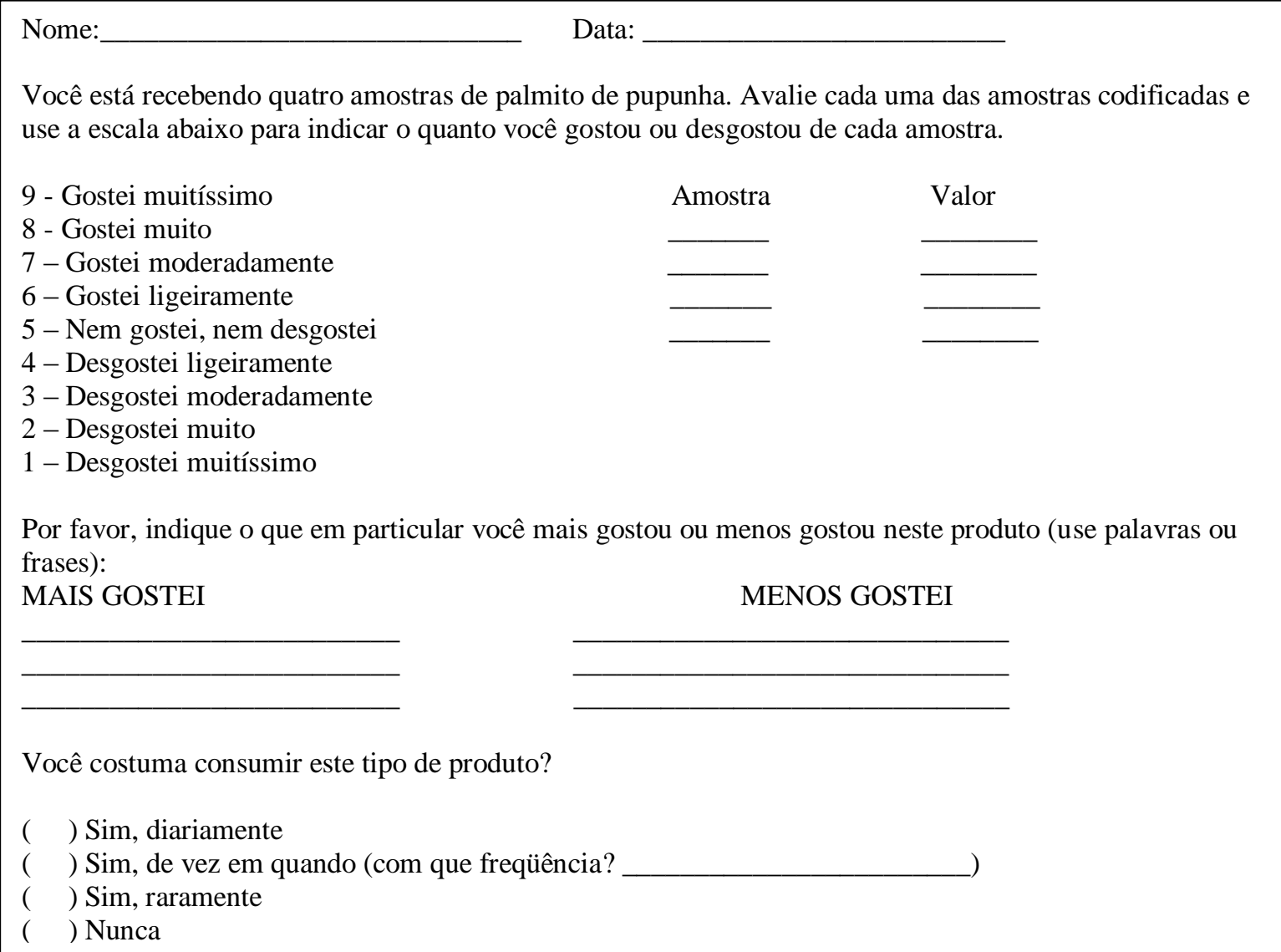

\section{Análise estatística dos resultados}

O conjunto de dados obtidos nas avaliações sensoriais foi analisado através do programa Statistical Analysis System (SAS, 2007) e submetido à análise de variância (ANOVA) para o teste F. A diferença estatística das médias, ao nível de significância de $5 \%(\mathrm{p}<0,05)$, foi determinada pelo teste de Tukey.

\section{Resultados e discussão}

No primeiro período de avaliação as conservas de palmito receberam as menores notas dos provadores, distinguindo-as das demais; isto se deve ao fato de o palmito entrar em equilíbrio com a salmoura em até 15 dias após o processamento, ocasião em que o produto adquire o sabor característico. Os provadores, nos demais períodos, colocaram em igual patamar de pontuação as 
conservas de palmito foliar e basal de pupunha, independentemente do tipo de ácido utilizado e dos períodos de armazenamento, não havendo diferença estatística entre eles (Tabela 1). Portanto, as amostras obtiveram a mesma aceitação, não importando se foram feitas de palmito foliar ou basal de pupunha e nem o tipo de ácido utilizado na acidificação. $O$ ácido acético não interferiu consideravelmente no sabor das amostras, embora o fato das notas estarem, algumas vezes, abaixo das atribuídas às conservas com ácido acético. Este acontecimento pode ser atribuído à sensibilidade dos provadores ao sabor amargo do ácido acético.

Tabela 1 - Impressão global de conservas de palmito basal e foliar de pupunha (B. gasipaes) submetidas à acidificação com os ácidos acético e cítrico e armazenadas em diferentes períodos (valores médios)

\begin{tabular}{ccccccc}
\hline & \multicolumn{7}{c}{ Períodos de armazenamento (dias) } \\
\hline Tratamentos & $\mathbf{1}$ & $\mathbf{1 5}$ & $\mathbf{3 0}$ & $\mathbf{6 0}$ & $\mathbf{9 0}$ & Médias \\
\hline PBAA & 4,50 & 5,43 & 4,33 & 4,90 & 4,93 & $4,82 \mathrm{c}$ \\
PBAC & 5,40 & 5,43 & 5,63 & 5,40 & 5,67 & $5,51 \mathrm{~b}$ \\
PFAA & 4,73 & 5,83 & 6,40 & 6,40 & 5,43 & $5,76 \mathrm{ab}$ \\
PFAC & 5,20 & 6,07 & 6,60 & 6,20 & 6,60 & $6,13 \mathrm{a}$ \\
\hline Médias & $4,96 \mathrm{~B}$ & $5,69 \mathrm{AB}$ & $5,74 \mathrm{~A}$ & $5,72 \mathrm{~A}$ & $5,66 \mathrm{AB}$ & - \\
\hline CV & $\mathbf{3 9 , 8 0 \%}$ & &
\end{tabular}

Nota: Médias seguidas pela mesma letra maíscula na linha e minúscula na coluna não diferem entre si ao nível de 5\% de probabilidade pelo Teste de Tukey; Legenda: palmito basal ácido acético (PBAA); palmito basal ácido cítrico (PBAC); palmito foliar ácido acético (PFAA); palmito foliar ácido cítrico (PFAC); coeficiente de variação (CV)

De acordo com as médias gerais entre os tratamentos, a maior nota foi conferida à conserva de palmito foliar com ác. Cítrico $(6,13)$ enquadrando-se na classificação "gostei ligeiramente"; já a menor nota refere-se ao palmito basal com ác. acético, classificado como "desgostei ligeiramente" $(4,82)$. As conservas de palmito foliar com ác. acético, basal e foliar com ác. cítrico podem ser consideradas equivalentes por não diferenciarem entre si, recebendo avaliação entre "nem gostei nem desgostei" e "gostei ligeiramente" (Tabela 1).

Para se ter uma idéia mais exata da preferência dos provadores, foi calculada a aceitabilidade proporcional (AP) (Equação 1) (CHAIMSOHN, 2003) dos indivíduos para o mesmo critério. Este índice mostra a porcentagem de pessoas que aprovaram o produto, para cada amostra em função do tempo de armazenamento (Tabela 2).

$$
A P=\frac{100 * M}{9}
$$

Eq.1

Onde, M é a média das notas e 9 é a nota máxima atribuída. 
Tabela 2 - Aceitabilidade proporcional (AP, \%) de conservas de palmito basal e foliar de pupunha (B. gasipaes) submetidas à acidificação com os ácidos acético e cítrico e armazenadas em diferentes períodos

\begin{tabular}{cccccc}
\hline & \multicolumn{5}{c}{ Períodos de armazenamento (dias) } \\
\hline Tratamentos & $\mathbf{1}$ & $\mathbf{1 5}$ & $\mathbf{3 0}$ & $\mathbf{6 0}$ & $\mathbf{9 0}$ \\
\hline PBAA & 49,62 & 60,37 & 48,15 & 54,44 & 54,81 \\
PBAC & 60,00 & 60,37 & 62,59 & 60,00 & 62,96 \\
PFAA & 52,59 & 64,81 & 71,11 & 71,11 & 60,37 \\
PFAC & 57,78 & 67,41 & 73,33 & 68,89 & 73,33 \\
\hline
\end{tabular}

Legenda: palmito basal ácido acético (PBAA); palmito basal ácido cítrico (PBAC); palmito foliar ácido acético (PFAA); palmito foliar ácido cítrico (PFAC).

Confirmando a tendência observada na Tabela 1, as amostras do primeiro período tiveram o menor índice de aceitação quando comparadas às dos demais, decorrente do provável sabor ácido ou amargo das amostras. Nos períodos posteriores foi observada elevação da aceitabilidade porporcional, em que as amostras apresentaram valores acima de $60 \%$, com exceção da conserva de palmito basal acidificada com ácido acético que apresentou para todos os períodos os menores índices. No geral, as conservas de palmito foliar, independentemente do ácido empregado, foram as mais bem aceitas em todos os períodos avaliados, tendo sido observado, ainda, constância dos valores atribuídos à conserva de palmito basal acidificado com ácido acético. As pequenas variações havidas nas taxas de aceitabilidade proporcional podem ser atribuídas aos diferentes níveis de percepção individual dos provadores, eis que não foram os mesmos em todas as sessões de avaliação sensorial.

Em todas as sessões foi perguntado aos provadores o que mais e/ou menos apreciaram sensorialmente nas amostras, sendo que os termos mencionados com maior frequencia diziam respeito ao sabor e textura (Tabela 3 ).

Tabela 3 - Avaliação geral das amostras de palmito foliar e basal ("mais gostei” e "menos gostei”)

\begin{tabular}{cc}
\hline Mais gostei & Menos gostei \\
\hline Sabor: picante (ácido), suave, adocicado, salgado, azedo & Sabor: vinagre, azedo, amargo, adocicado, ácido, \\
Textura: macia, crocante, firme & salgado, forte, residual, óleo \\
Aparência: cor & Textura: fibrosa, mole, dura \\
Aroma & Aparência: cor forte \\
Aroma forte
\end{tabular}

A análise da frequencia de consumo de palmito de pupunha indicou que a grande maioria dos provadores consome o produto "às vezes", e muitos deles "raramente" (Figura 2). Estes valores são parecidos com os encontrados em pesquisa realizada por Verruma-Bernardi et al. (2003), que em sua análise sensorial de palmito de pupunha, $78 \%$ dos provadores alegaram consumir o produto uma vez ao mês. Este hábito de consumo pode ser explicado pelo palmito ser uma iguaria que possui valores altos no mercado, fazendo com que as pessoas não tenham o costume em utilizá-la na alimentação. 
Figura 2 - Freqüência de consumo de palmito pelos provadores

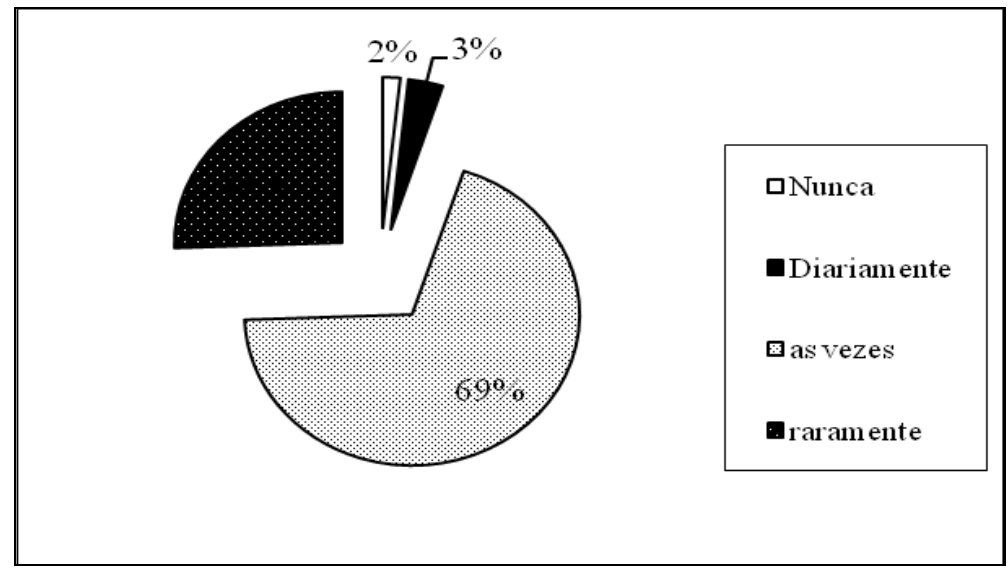

\title{
4 Conclusão
}

Sensorialmente, o tolete e o palmito basal de pupunha possuem as características similares, podendo ser comercializados na mesma categoria. O ácido acético conferiu gosto ligeiramente ácido ou amargo às amostras, porém não interferiu negativamente em suas avaliações, mostrando que pode ser utilizado na acidificação das conservas em substituição ao ácido cítrico, amplamente usado nas indústrias palmiteiras.

\begin{abstract}
The peach palm, native of Amazon, has characteristics of early maturity, hardiness and tiller number, provides excellent quality, differing from the others by a sweet flavor and yellowish color. Due to this fact, this product is not well accepted because the sensory taste of consumers is accustomed to canned palm saltier. The industry traditionally uses citric acid in the processing of canned palm heart, however, acetic acid has the ability to mask the sweet taste of peach palm. The aim of this study was to evaluate sensory preserved basal and palm leaf acidified with acetic acid, compared to those processed with citric acid. The palms were cultivated in experimental area of ESALQ/USP and had the sensory characteristics of basal and palm leaf analyzed in five storage periods $(1,15,30,60,90$ days). The mean values for the attribute overall impression showed less acceptance of canned palm basal acidified with acetic acid, classified as "dislike slightly", but did not differ statistically from the other products, which were well accepted in all periods, highlighting the samples of palm leaf. Acetic acid samples gave the slightly bitter taste, but not the negative impact on their evaluations, showing that could be used instead of citric acid. Still, it was found that the palm can be traded equaly to the leaf level, because there was no statistical difference between them.
\end{abstract}

Key-words: Bactris gasipaes, acceptance testing, thermal processing, citric acid.

\section{Referências}

ALMEYDA, N.; MARTIN, F. W. The pejibaye. In: Cultivation of neglected tropical fruits with promise. Department of Agricultural of United States; Washington, 1980. 8p. 
BOVI, M. L. A. Palmito pupunha: informações básicas para o cultivo. In: CAMARGO, G. M. S.; FURIA, L. R. R. Encontro sobre produção de palmito, Piracicaba: Centro Acadêmico Luiz de Queiroz (CALQ), 1993. p.12-23.

CHAIMSOHN, F. P. Cultivo de pupunha para palmito. Importância, mercado e aspectos biológicos e agronômicos. In: CHAIMSOHN, F. P. (Coord.). Curso sobre cultivo e processamento de palmito de pupunha e introdução ao cultivo de palmeira real para palmito. Londrina: Instituto Agronômico do Paraná, IAPAR, 2001. p. 4-149.

CHAIMSOHN, F. P. Análise sensorial de palmito de Pupunha in natura. Revista de Agricultura, Piracicaba, v. 78, n. 3, 2003. p. 405-411.

COCHRAN, W. G.; COX, G. M. Experimental designs. 2th ed. New York: John Wiley, 1957. 618p.

MEIlgAARD, M. CIVILlE, V.; CARR, B. T. Sensory evaluation techniques. 2ed. Boca Raton: CRC Press, 1991. $354 \mathrm{p}$.

MORA-URPÍ, J. Origem y domesticación. In: MORA-URPÍ, J.; GAINZA, E. Palmito de Pejibaye (Bactris gasipaes Kunth): su cultivo e industrialización, San José: Universidad de Costa Rica, 1999. p.17-25.

MUÑOZ, A. M.; CIVILle, G. V.; CARR, B. T. Sensory evaluation in quality control. New York: Van Nostrand Reinhold, 1992. 240 p.

RAUPP, D. S. O Envase de palmito de pupunha em vidro. In: CHAIMSOHN, F. P.; SKORA NETO, F.; SANTOS, A. F.; TESSMANN, D. J.; DURIGAN, M. E.; TREITNY, M. R.; HERNADEZ, F. B. T.; RAUPP, D. S. Curso sobre cultivo e processamento de palmito de pupunha e Introdução ao cultivo de palmeira real para palmito. Londrina: Instituto Agronômico do Paraná, IAPAR, 2001. p. 127-138.

SOCCOL, M. C. H. Otimização da vida útil da tilápia cultivada (Oreochromis niloticus) minimamente processada e armazenada sob refrigeração. 2002. 124p. Dissertação (Mestrado em Ciência e Tecnologia de Alimentos) - Escola Superior de Agricultura “Luiz de Queiroz”, Universidade de São Paulo, Piracicaba, 2002.

STATISTICAL ANALISIS SYSTEM INSTITUTE. SAS/QC software: usage and reference (version 9.2). Cary, 2007. CDROM.

VERRUMA-BERNARDI, M. R.; CAVALCANTI, A. C. D.; KAJISHIMA, S. Aceitabilidade do palmito de Pupunha. Boletim do Centro de Pesquisa e Processamento de Alimentos, Curitiba, v.21, n.1, p.121-130, jan./jun., 2003.

YUYAMA, K. Sistemas de cultivo para produção de palmito da pupunheira. Horticultura Brasileira, Brasília, v.15, p.191-198, 1997.

YUYAMA, K. Melhoramento de pupunheira para produção de palmito no INPA. In: REUNIÃO TÉCNICA DO PROJETO DE PROBIO/MMA PUPUNHA - RAÇAS PRIMITIVAS E PARENTES SILVESTRES, sn. 2005, Manaus, Amazonas. Relatório... Manaus, Amazonas: INPA, 2005.

ZAPATA, M. M.; QUAST, D. G. Curvas de titulação do palmito-doce (Euterpe edulis Mart.). Coletânea do Instituto de Tecnologia de Alimentos, Campinas, v.6, p.167-187, 1975.

Submetido em 03 set. 2011; Revisão submetida pelos autores em 31 nov. 2011; Aceito para publicação em 09 dez.2011. 